\title{
A Historical Perspective of Treatment and Discharge Planning for the Seriously, Chronically, Mentally Ill Patient: A Review of the Literature
}

Simona Dlabal ${ }^{1}$ and Brenda Marshall ${ }^{2^{*}}$

${ }^{1}$ Lincoln Medical and Mental Health Center, New York City Health and Hospitals Corporation, USA

${ }^{2}$ Department of Nursing, William Paterson University, NJ, USA

"Corresponding author: Brenda Marshall, EdD, APRN, ANEF, Associate Professor, Department of Nursing, William Paterson University, NJ, USA, Tel: 9736857000, Email: MARSHALLB3@wpunj.edu

Received date: Jul 14, 2016, Accepted date: Feb 20, 2017, Published date: Feb 27, 2017

Copyright: (C) 2017 Dlabal, S. This is an open-access article distributed under the terms of the Creative Commons Attribution License, which permits unrestricted use, distribution, and reproduction in any medium, provided the original author and source are credited.

\begin{abstract}
The movement from institutionalized care to community and home care is evident in all aspects of health care. This shift began in the 1950's in the United States changing the inpatient and outpatient treatment of the chronically mentally ill. The nature of psychiatric illness, however, differs significantly from other ailments. The stigma of mental illness, combined with the cardinal symptom of lack of self-care, often leaves the patient vulnerable impacting safe discharge to the family and community. Advances in mental health care, increased pressure from the public, and changing federal policies over the last six decades have contributed to the American shift towards a more community-centered care model. This review of the literature will examine three defining periods reflecting shifts in care paradigms (1950-1975, 1976-1995, and 1996-2015), and the subsequent changes in treatment provision for the seriously, chronically mentally ill in the United States.
\end{abstract}

Keywords: Historical perspective; seriously, chronically mentally ill; discharge planning

\section{Introduction}

The movement from institutionalized care to community and home care is evident in all aspects of health care. This shift has been occurring in the United States in treating the chronically mentally ill as well. The nature of psychiatric illness, however, differs significantly from other ailments. The stigma of mental illness, combined with the cardinal symptom of lack of self-care, leaves the patient vulnerable and impacts safe discharge to the community.

Advances in mental health care, increased pressure from the public, and changing federal policies over the last six decades have contributed to the American shift towards a more community-centered care model. Patients with serious, chronic, mental illness, however, often require frequent hospitalizations for stabilization and ongoing support in order to achieve recovery and optimal functioning in society.

Schizophrenia is a serious, and often disabling mental illness affecting approximately $1.1 \%$ of adults, (Macleod et al [1]). Over 51 million people are diagnosed with schizophrenia worldwide, with 2.8 million in the United States. The average age at onset is 16 to 30 years old, affecting males earlier than females. There are several types of schizophrenia, and people diagnosed with schizophrenia exhibit different symptoms with various degrees of severity, ranging from mild to severe.

This review of the literature will examine three defining periods reflecting shifts in care paradigms (1950-1975, 1976-1995, and 1996-2015), and the subsequent changes in treatment provision for the seriously, chronically mentally ill, examining the subset of persons diagnosed with schizophrenia, in the United States.

\section{Historical perspective}

Early in the 17th century persons with mental illness were treated at home by their families, jailed or tried and hung as witches (Hollingshead et al. [2]). The encarcerated, mentally ill individual could be legally sold into labor, ridding the jail of the problem and providing cheap workers to the neighboring farms. They were people not wanted by their families, their communities or their states. Their symptoms made them difficult to employ and dangerous to provide shelter to. The number of mentally ill patients incarcerated in assylums in the United States by 1956 was estimated at 600,000 (Koyanagi [3], Although the first hospital for the mentally ill was established in New Haven, Connecticut in 1822, the plight of the mentally ill did not improve. These asylums were developed to segregate the mentally ill from those with acute medical problems, and were seen as "dumping grounds", not as therapeutic environments conducive for recovery. The first clinic that was opened for the mentally ill arrived in the early 1950's in New Haven Connecticut, coinciding with the development of new drugs, specifically thorzine in 1954, which reduced some of the symptoms of psychosis, and marked the first paradigm shift in treatment of the psychotic, mentally ill American.

Advances in mental health care, increased pressure from the public, and changing federal policies over the last six decades have contributed to the American shift towards a more community-centered care model (Goldberg et al. [4]). The person with schizophrenia frequently depends on others to function in society. Patients, and their caregivers, often feel unprepared for the transition from hospital to community, resulting in increased stress levels, ineffective coping, social isolation, and overall lower quality of life (Khaleghparast et al. [5]). Discharge planning is an essential component of patient care (Bauer et al. [6]). It is the "process of identifying and preparing for the patient's anticipated health care needs on discharge from a facility" Maramba et al. as quoted in Bauer et al [6]). It acts as a bridge between acute hospitalization and functioning in the community. 
Caregivers, often parents, partners, siblings, or other close relatives, are also significantly affected by the plight of the patient diagnosed with a serious, chronic mental illness like schizophrenia (Suro et al. [7]). Families are often driven by a sense of duty toward the mentally ill and are committed to providing care and support. The chronic and recurrent nature of the illness, along with the unpredictability of the inappropriate behaviors, poor motivation for treatment, hygiene, and social interactions, pose daily stressors the patients and caregivers. Examining the three periods of interest (1950-1975, 1976-1995, and 1996-2015) provides a framework that clarifies the changing paradigms in America, and the impact those beliefs and policies have had on the treatment of, and discharge planning for, the seriously, chronically mentally ill.

\section{Methodology}

The Cumulative Index to Nursing and Allied Health Literature (CINAHL), PsychInfo, and Medline databases were used in this search. Key words and phrases used were: Discharge planning, discharge education, psychosis and mental illness. The search was divided into three chronological categories 1950-1975, 1976-1995, 1996-2015, timeframes reflective of American policy changes, which resulted in a reduction of inpatient beds and a focus progressively shifting towards community care.

Chronological parameters: Choronological parameters were determined by paradigm and policy shifts in american health. The first parameter, 1950-1975, is reflective of the policy of institutionalization on large scale and the introduction of antipsychotic drugs. The paradigm shift from institution to outpatient occurred between 1976-1995, which is identified as the second time period for examination. The treatment model shifted again, from outpatient care to independence and community setting during the period of 1996-2015.

Inclusion factors: Articles published in English, relating to chronic mental illness and discharge planning for the mentally ill. Key words included family planning, mental illness, political impact, policy, and discharge planning.

Additional inclusion factors: Articles were included if they met three criteria; 1) the discussion focused on American treatment of psychosis within the identified time frame, 2) the article included American policy as a variable in changing treatment, and 3) discharge planning for the patient was discussed.

Results: A broad review of abstracts fitting the criteria revealed 300 articles discussing discharge planning related to policy within the time periods. The final synthesis, using the three additional criteria, resulted in 17 articles. Five articles related to policies of 1950-1975 (Table 1), six articles from 1976-1995 (Table 2), and six from 1996-2015 (Table 3).

\begin{tabular}{|c|c|c|c|c|}
\hline Author (year) & Aim of study & Country & Research Design & Main Findings \\
\hline Baker F [8] & $\begin{array}{l}\text { To evaluate the orientation of mental } \\
\text { health professionals toward human } \\
\text { services }\end{array}$ & USA & Discussion & $\begin{array}{l}\text { Mental health care services were becoming } \\
\text { increasingly inclusive and comprehensive }\end{array}$ \\
\hline Locke BZ [9] & $\begin{array}{l}\text { To evaluate outcomes of first } \\
\text { hospitalizations of schizophrenia } \\
\text { patients prior to use of tranquilizers }\end{array}$ & USA & $\begin{array}{l}\text { Retrospective quantitative } \\
\text { design }\end{array}$ & $\begin{array}{l}40 \% \text { of first time admitted patients were } \\
\text { within } 6 \text { months. Shorter stays were observed } \\
\text { in younger, employed, educated, and married } \\
\text { patient from metropolitan areas. }\end{array}$ \\
\hline Rohde et al. [10] & $\begin{array}{l}\text { To evaluate effectiveness of treatment } \\
\text { of Schizophrenic patients in a general } \\
\text { hospital unit }\end{array}$ & UK & Quantitative Design & $\begin{array}{l}\text { The results of a follow up of } 95 \text { schizophrenic } \\
\text { patients treated in the past } 10 \text { years showed } \\
\text { that } 82 \text { were not in hospital at time of study }\end{array}$ \\
\hline Silverman [28] & $\begin{array}{l}\text { To evaluate effectiveness of referral for } \\
\text { outpatient follow up }\end{array}$ & UK & $\begin{array}{l}\text { Longitudinal observational } \\
\text { study }\end{array}$ & $\begin{array}{l}\text { Readmission was reduced to } 50 \% \text { when } \\
\text { referrals for outpatient follow up was provided }\end{array}$ \\
\hline Wing et al. [11] & $\begin{array}{l}\text { To evaluate length of stay and rates of } \\
\text { readmission comparing traditional to } \\
\text { modern treatment }\end{array}$ & UK & $\begin{array}{l}\text { Longitudinal observational } \\
\text { study }\end{array}$ & $\begin{array}{l}38 \% \text { of patients under traditional treatment } \\
\text { were hospitalized for } 2 \text { cont. years as } \\
\text { compared to } 20 \% \text { on "modern" treatment }\end{array}$ \\
\hline
\end{tabular}

Table 1: Summary tables of studies from 1950-present historical review.

\begin{tabular}{|c|c|c|c|c|}
\hline Author (year) & Aim of study & Country & Research Design & Main Findings \\
\hline Curson et al. [13] & $\begin{array}{l}\text { To assess the severity of illness among the } \\
\text { hospitalized patients and implications for their } \\
\text { future care in the community }\end{array}$ & UK & Survey/interviews & $\begin{array}{l}\text { Of the } 222 \text { hospitalized patients, } 194 \\
\text { exhibited florid sychotic symptoms or } \\
\text { presented behaviors that would set them } \\
\text { apart in the community }\end{array}$ \\
\hline Farina et al. [17] & $\begin{array}{l}\text { To evaluate consequences of changing people's } \\
\text { views regarding the nature of mental illness }\end{array}$ & USA & $\begin{array}{l}\text { Questionnaires and journal } \\
\text { keeping }\end{array}$ & $\begin{array}{l}\text { Benefits were seen in shifting public } \\
\text { beliefs toward viewing mental illness as a } \\
\text { learning problem rather than a disease }\end{array}$ \\
\hline $\begin{array}{l}\text { Gruenberg et al. } \\
\text { [12] }\end{array}$ & $\begin{array}{l}\text { To evaluate the shift from institutionalization to } \\
\text { deinstitutionalization }\end{array}$ & USA & Narrative literature review & $\begin{array}{l}\text { The shift led to community neglect and } \\
\text { deprivation of clinical services }\end{array}$ \\
\hline
\end{tabular}




\begin{tabular}{|c|c|c|c|c|}
\hline Kanter et al. [16] & $\begin{array}{l}\text { To evaluate the use of Expressed Emotion in } \\
\text { predicting schizophrenic patient relapse }\end{array}$ & USA & Literature Review & $\begin{array}{l}\text { Expressed emotion may predict relapse } \\
\text { but it likely does not cause relapse }\end{array}$ \\
\hline Melzer et al. [15] & $\begin{array}{l}\text { To evaluate effectiveness of community care in } \\
\text { schizophrenic patients one year after discharge }\end{array}$ & UK & Cross sectional surveys & $\begin{array}{l}\text { Many patients suffered from symptoms } \\
\text { upon discharge. These patients required } \\
\text { high level of outpatient care and } \\
\text { assistance with accommodation. }\end{array}$ \\
\hline $\begin{array}{l}\text { Weinstein } \quad \text { RM } \\
\text { [14]. }\end{array}$ & $\begin{array}{l}\text { To evaluate patient attitudes toward mental } \\
\text { hospitalization }\end{array}$ & USA & $\begin{array}{l}\text { Review of Quantitative } \\
\text { research }\end{array}$ & $\begin{array}{l}\text { Patients were favorable towards } \\
\text { hospitalization }\end{array}$ \\
\hline
\end{tabular}

Table 2: Summary tables of studies from 1950-present historical review.

\begin{tabular}{|c|c|c|c|c|}
\hline Author (year) & Aim of study & Country & Research Design & Main Findings \\
\hline Gerson et al. [20] & $\begin{array}{l}\text { To explore perceptions of patients and families of } \\
\text { patients' needs, functioning, coping and social } \\
\text { support in the first } 4 \text { weeks after inpatient treatment }\end{array}$ & USA & Descriptive study & $\begin{array}{l}\text { Patients had residual symptoms after } \\
\text { discharge that interfered with } \\
\text { functioning despite the availability of } \\
\text { follow-up services. } \\
\text { Both patients and families seemed to } \\
\text { lack a thorough understanding of goals } \\
\text { for follow-up care. }\end{array}$ \\
\hline Habibi et al. [21] & $\begin{array}{l}\text { To investigate special educational needs of } \\
\text { schizophrenic patients and their families }\end{array}$ & Iran & Systematic literature review & $\begin{array}{l}\text { The educational needs include six } \\
\text { dimensions: social interactions, support } \\
\text { resources, knowledge, coping, stigma, } \\
\text { quality of life }\end{array}$ \\
\hline Hawthorn et al. [19] & $\begin{array}{l}\text { To examine rates and risk factors of incarceration } \\
\text { among psychiatric patients }\end{array}$ & USA & $\begin{array}{l}\text { Retrospective quantitative } \\
\text { design }\end{array}$ & $\begin{array}{l}\text { Modifiable factors affecting } \\
\text { incarceration include homelessness, } \\
\text { substance abuse, lack of medical } \\
\text { insurance, outpatient care }\end{array}$ \\
\hline $\begin{array}{l}\text { Khaleghparast et al. } \\
{[5]}\end{array}$ & $\begin{array}{l}\text { To investigate the effectiveness of discharge } \\
\text { planning on the knowledge, clinical symptoms, and } \\
\text { readmission rates }\end{array}$ & Iran & Longitudinal clinical trial & $\begin{array}{l}\text { Discharge planning benefits: increased } \\
\text { knowledge, decreased symptoms and } \\
\text { readmissions }\end{array}$ \\
\hline Lamb et al. [18] & $\begin{array}{l}\text { To evaluate the shift of inpatient psychiatric care } \\
\text { from hospitals to prisons }\end{array}$ & USA & Discussion & $\begin{array}{l}\text { Some patients require a high quality } \\
\text { structured inpatient treatment instead of } \\
\text { outpatient services }\end{array}$ \\
\hline Macleod et al. [1] & $\begin{array}{l}\text { To identify approaches that could be delivered } \\
\text { within community practice to reduce burden and } \\
\text { increase knowledge, mental health and coping }\end{array}$ & USA & Systematic literature review & $\begin{array}{l}\text { Education improves caregivers' } \\
\text { knowledge of schizophrenia } \\
\text { Supportive family education, } \\
\text { community support, and support groups } \\
\text { can improve burden, coping or mental } \\
\text { health }\end{array}$ \\
\hline
\end{tabular}

Table 3: Summary tables of studies from 1950-present historical review.

\section{Historical research-model 1: 1950-1975}

The six main themes recognized during this era of change are as follows: movement towards shorter hospitalizations; team approach; introduction of neuroleptic and antipsychotic drugs; continuity of care after hospitalization; development of comprehensive outpatient programs; and rehabilitation efforts in the community, such as aid with employment and housing [8-12].

Baker [8] identified that during the 1950s mental hospitals were no longer recognized an individual institution, but rather as a collective effort of a community of people. Following this shift, mental health professionals in the 1960s were gradually expanding their practices from solely inpatient institutions to community settings. The mental health professionals were encouraged to follow the new belief system to extend their roles and practices, creating an elaborate network of care.
A major shift from long hospitalization began in the 1950s. Forty eight percent of patients under 34 years of age, diagnosed with schizophrenia, were discharged within six months of admission. All patients with diagnosis of mental illness did not fare as well, with 70 to $80 \%$ being hospitalized for periods of two to five years with the remainder still hospitalized past the five year period. Wing et al. [12] reported that of the patients with a new diagnosis of schizophrenia in 1950 , approximately $40 \%$ were hospitalized for over two years. The rates dropped to $20 \%$ ive years later, after the introduction of the medication Thorzine and introduction of outpatient services for the mentally ill. Despite the shorter stays, however, no significant increase in re-admissions were noted.

The positive change in community attitudes toward schizophrenia, and the apparent successful treatment with medication, was identified as having a positive influence on community responsibility for the mentally ill. During this time, the outpatient setting became a 
collaborative effort, placing the patient in the position of a voluntary member of the team. The introduction of neuroleptic drugs, outpatient medication administration, and long-acting injectable medications also played an important role, gradually replacing formal E.C.T, insulin coma, and leucotomy treatments. Group therapies were introduced during this time period, as part of the treatment options [13-23].

Improvement in discharge planning was recognized as another important step towards shortened hospitalizations. The team approach to the treatment of psychiatric patient brought vital changes to the course of therapy. The traditional psychiatrist-patient relationship expanded to include social workers, physicians, occupational therapists, registered nurses, and clinic nurses, with optional involvement of psychologist and a chaplain. The patient's family played a crucial role in discharge planning as well. Patients without families or visitors had significantly longer hospitalizations, lasting two years or longer (Andrews et al. [23]).

Lack of housing caused lengthy hospitalizations and increased readmissions, making the collective efforts of family and community critical. The hospital environment was preferred by some, especially the homeless. The role of social workers and occupational therapists expanded during this time to include helping mentally ill patients beyond the period of hospitalization with housing and employment, aiding their return to the community setting [24-27].

Silverman [28] followed patients for three years post discharge, who prior to release, were referred to outpatient supervision by a mental welfare officer and psychiatric social worker. These patients were carefully selected during regular scheduled meetings attended by key healthcare providers as part of the discharge planning. These meetings were found to be beneficial as they allowed for effective communication among the clinicians. This resulted in selection of appropriate candidates most likely to gain from outpatient services, such as follow up appointments, assistance with housing and employment, thus decreasing rates of readmission and burden on society.

\section{Paradigm shift 2: 1976-1995}

The paradigm of the 50's supported the mass institutionalization of the mentally ill. As the country moved towards a new paradigm citing asylums and large hospitals as providing inhumane care, federal and state policy-making shifted towards deinstitutionalization of the chronically mentally ill. This change brought new sets of problems to the provision of care to the mentally ill. Large psychiatric hospitals, portrayed as repugnant, were closed, and many patients lacked the access to needed help.

The previously increasing readmission rates reached new heights. The nacent planned continuity of community began failing patients due to gaps in accessibility. Abuse of drug and alcohol rose among the discharged patients, homelessness of psychotic patients or those with poor social skills was common, and patients released to alternate care, such as nursing homes and other adult residencies failed to improve. Increased groups of mentally ill were denied long-term hospital care and supervision based on new policies. Although the process of shifting responsibility from state governments to other agencies and caregivers began with the best intentions, it became evident that the gap in organizing and planning for community services led to the abandonment of mentally ill patients. Despite increased interest and financial investments, community agencies and families were inadequately equipped to provide full time, long-term care of the seriously mentally ill.

Gruenberg et al. [13] identified several issues leading to this failure. There was a spurious association drawn between the low census in psychiatric hospitals and a well-functioning system that was resulting in patient improvement. In fact, the implementation of policies resulting in shorter hospital stays, while resulting in an overall low number of daily occupied beds, produced higher readmission rates. Gruenberg et al. [13] asserted that higher rates of readmission should not be necessarily perceived as negative measure, since shorter hospitalizations naturally created increased need for readmissions, and these patients should not be denied easy access to care. Curson et al. [14] pointed to the large numbers of patients, especially the elderly, who despite prolonged hospitalizations and use of modern treatment, were clearly not ready for discharge to the community.

Curson et al. [14] identified that hospitalization should not be needlessly prolonged to prevent diminishing of patient's ability to function in the community, however, when warranted, it was necessary. State hospital care was identified as excessively confining and humiliating, therefore the trend was to attempt to replace it by community care. In cases where this proved impossible, the new alternative options of nursing homes and locked psychiatric wards were introduced. Unfortunately these environments were no better than those of the state hospitals, and sometimes even more restrictive to the patients.

Where it was possible, patients were admitted into short-term hospitalizations, which prevented long-term stays. The short term admissions resolved the acute symptoms and providing immediate relief to family care givers. Patients reported positive attitudes toward short hospitalizations and community resources, citing beneficial gains from treatment, activities, staff interaction, a safe environment, improved insight into their condition, and opportunities for selfimprovement. In contrast, other patients reported that the available community resources and services were of such low quality, they were better off not using them (Melzer et al. [15]).

The shift towards community care placed a considerable amount of responsibility on the caregivers. A long or difficult strain can lead to caregiver burnout, resulting in complete abandonment of the patient found that while the family's attitudes and behaviors do not cause the mental illness, they have the power to exacerbate a preexisting disorder.

Farina et al. [17] considered effect of public messaging about mental health on public opinion. Their findings stated that opinions are malleable and change with the information provided to them. They evaluated two methods; a blaming approach, identifying psychotic behaviors on a disease process, much like a pneumonia or diabetes, and the assignment of the symptoms of psychosis to a learned pattern of behaviors.

The findings were not uniformly clear but suggested that there may be benefits from portraying mental illness as learning disability. The researchers found that by implying that it was a disease, the stigma associated with this condition continued, and the public tended to promote the perceived helplessness of the patient. This was likely to slow patient progress reducing patient acceptance of the situation, and supporting an unwillingness, and hopelessness in successful behavior change. Associating the symptoms with a learned behavior, however, increased patient active participation in learning about behavioral adjustment. The patient had an active role in the future, rather being a 
passive victim, waiting for doctor's cure. No significant changes were measured, however, in relieving shame associated with the condition or alleviating family's sense of guilt.

Gruenberg et al. [12] and Melzer et al. [15] discussed individualized care. Chronic patients, especially those with highest need, underused the available community resources. Developing a tailored approach seemed to be the next logical step. This was formulated in the role of a case manager, who could provide a bridge between the fragmented services. This ensured continuity of care, and was able to reach those patients who would otherwise have fallen through the cracks (Melzer et al. [15]). Gruenberg et al. [12] argued against this alternative, stating that a case manager would merely provide ways to cope with the fragmented services, not repair the system.

\section{Model shift 3: 1996-2015}

The gradual shift towards deinstitutionalization delivered a stark reality, while the numbers of mental hospital beds continued to decline, the numbers of psychiatric patients did not. Untreated or noncompliant patients exhibiting bizarre or violent symptoms, required a place to keep themselves and the public safe (Hawthorne et al. [19]). Large populations of psychiatric patients, those who would previously have been admitted to inpatient psychiatry, were now being incarcerated instead. The number of state hospital beds in the United States, by the year 2000, declined from its peak in 1955 of 339 per 100,000 to 22 per 100,000 of population. This was accompanied by a jump in numbers of inmates from 209 per 100,000 in 1978 to 708 per 100,000 . It was estimated that approximately 113 of those 708 inmates were mentally ill. When added, there were at least 135 per 100,000 or close to 370,000 of mentally ill patients locked in a form of involuntary, structured setting during that year.

These statistics continued to rise and by 2007 , an estimated $64 \%$ of incarcerated inmates exhibited symptoms of mental illness (Hawthorne et al. [19]). Mentally ill patients are one of the most vulnerable populations, and are at increased risk for recidivism as well as repeated incarceration. Hawthorne et al. [19] highlighted some of the modifiable factors that affect incarceration risk including homelessness, substance abuse, lack of health insurance, and absence of timely outpatient services.

According to Weinberger et al. [18], society was increasingly reluctant to fund mental health care in all its forms. There was a concurrent effort to relocate funding used on the remaining inpatient beds towards community treatment. All this occurred with a growing criminal justice system hearing little resistance from public and legislators to provide sufficient funds to treat the incarcerated mentally ill. Psychiatric care provided in U.S. prisons uses trained professionals, provides structure, therapeutic activities and appropriate medications but it is an inadequate replacement of the traditional mental health system.

The literature from the era of 1995 to 2015 identified the importance of family involvement, due to the incremental, ongoing shift of responsibility from health care providers to patients and their caregivers. Accessibility of community resources, effective interdisciplinary communication and active, engaged discharge planning is imperative for patient success. Increasingly, the numbers of approved inpatient hospitalizations were limited to a few days, causing a major shift of responsibility to the patient and willing family members. Unfortunately, this solution often failed to provide sufficient time for stabilization, location of housing, and involvement and education of the patient's family. Inadequate planning, even when the caregivers were involved, left them with the burden of ensuring the patients follow up with their outpatient care, medication compliance, and symptom management. The caregivers reported feeling unprepared for the role expressing their poor understanding of the psychiatric patient's needs. Most patients and caregivers found discharge instructions insufficient, or explained that they did not understand the goals of follow up care. Some families expressed concerns regarding lack of resources on follow up care, outpatient services, medication management, and overall limited information regarding post-discharge care. The authors pointed out that although comprehensive treatment programs are often available in the communities, their effectiveness could be greatly improved though a few initiatives. These include establishing clear treatment goals, explaining the program's expectations, and by creating a strong therapeutic union with the families and patients. Gerson et al. [20] also associated caregivers' burnout to the severity of the patient's symptoms and needs, and identified the significance of including the support of caregivers in the care plan.

Khaleghparast et al. [5] stated that the hospital discharge process poses a stressful time for the patients and their families. Treatment compliance improves if careful discharge planning and post discharge treatment are in place. The impact of implementing a discharge plan with schizophrenic patients was studied in several hospitals. Previous findings suggested that the readmission rates of patients diagnosed were very high, possibly reaching $67 \%$. Low patient knowledge regarding treatment was identified as being to blame (Khaleghparast et al. [5]). Examining the effectiveness of discharge planning on the knowledge, clinical symptoms, and rates of re-hospitalization in schizophrenia patients identified appropriate discharge planning to be effective in improving patient's and caregiver's knowledge (Khaleghparast et al. [5]). Subsequently, discharge planning improved post-discharge quality of life, empowered patients and their families to take charge of their health, increased independence, decreased readmission rate, $s$ and medical costs.

Habibi et al. [21] evaluated the specific educational needs of families of patients with schizophrenia. Their research indicated family involvement and education was brought in the last 15 years, as they were increasingly recognized as the main source of long-term care for schizophrenic patient. The authors discussed the detrimental effects of the condition on the entire family unit and the need to involve caregivers in the discharge process, claiming that any attempts at a discharge teaching that does not include family is bound to fail.

When families lack sufficient knowledge and understanding of the disease, they may wrongly blame themselves, experiencing unnecessary grief that can lead to stress and isolation. When families are insufficiently prepared to monitor patient's behavior and treatment, they cannot act to their full potential, nor to the benefit of the patient. Accurate assessment of the family's specific educational needs allows for individualized approach. The six main areas of educational needs that were identified by Habibi et al. [21] were social interactions; sources of support; disease understanding; stigma; coping; and improving quality of life.

Macleod et al. [1], concurring with previous findings, identified the substantial burden of caring for the person with schizophrenia, leading to mental health problems, stress, and loneliness in caregivers. It was identified that mental health professionals can have a significant impact on these negative effects through providing support, education, and information leading caregivers to meaningful resources. 
Alleviating the level of burden sensed by the caregivers, and improving care for patients with schizophrenia could eventually lead to important health, social, and economic effects for the families.

Multiple interventions were considered by Macleod et al. [1]. Education was one of the primary intervention discussed. Education could be delivered through individual or group interventions, utilizing various settings, delivered by psychiatrists, nurses, and other clinicians, over various time settings from brief intervention to long term therapeutic alliances. Methods of delivering support through education was also discussed, with numerous options including interviews, lectures, booklets, and presentations. This approach grew from their theory that increased knowledge regarding the disease, and methodologies for treatment, can deliver benefits to the caregiver and ultimately to the patient. Evaluation of the results of this study, however, suggested that although this form of intervention improved the caregivers' knowledge, it did not necessarily benefit their coping abilities, decreasing level of burden, or improving their mental health.

Macleod et al. [1] discussed an alternative method to increase knowledge called supportive family education therapy (SFET). SFET was lead nurses trained in the approach, and was focused on developing coping strategies and support mechanisms for the caregivers. The aim of this approach was improving coping, social support, and overall quality of life for families of patients with schizophrenia. Results of this study indicated success in all areas except changing the physical or mental health of the individuals involved. A limitation identified by Macleod et al. [1] indicated that due to the multifactorial approach of the study, it was difficult to distinguish between which interventions, and specific aspects of individual programs, were actually efficacious.

Many family interventions were being examined during this period with focused, main goals of medication compliance, improved communication, problem solving, education, and social networking. The two most common interventions were behavioral family therapy (BFT) Macleod et al. [1] and cognitive behavioral family therapy (Barrow-clough et al. 1998 as cited in Macleod et al. [1]). These interventions were predominantly nurse-lead, and came with mixed findings. Behavioral family therapy appeared to be superior to any other intervention in reducing family care burden, improving in family coping, and increasing knowledge.

Macleod et al. [1] also evaluated the impact of community support services, consisting of case management, assertive outreach, community visits, and daily living programs. These programs, led by community mental health nurses, were found to be effective in burden reduction, however they were often costly and therefore less attractive. They were specific to community support and therefore not applicable to utilization in the acute care setting.

Mutual support groups, led by non-professional caregivers focused primarily on individual empowerment and improved social support. Evaluations of these programs were mainly positive in all studied categories but it was concluded that more studies are required in this area. Day care was the last intervention studied and one with the least representation. Only three studies with small numbers were available but none presented with notable improvements in any category.

\section{Current practice developments}

Comprehensive discharge planning was found to be one of the effective ways to decrease hospital readmissions and recidivism, enhance treatment compliance, and lower the cost of care. Currently, no gold standard for the discharge process exists, however certain guidelines, based on available frameworks and findings of previous studies, hold promise.

The "self-care training program" begins upon patient's admission, evaluates his progress and educational needs in preparation for a smooth transfer into the community. This program incorporates communication among the patient and members of the health care team, educates him regarding his condition, options, and most importantly improves independence by empowering him to take responsibility of his own health.

Effective therapeutic communication, placing the patient at the center of care through the evaluation of individual educational needs, is an important method to ensure continuity of care. It includes the involvement of the health care team members focused on planning an appropriate, individualized intervention upon discharge, preparing the patient, family and community access to support during the ongoing recovery period. Providing patients with follow up appointments, prior to discharge, is another important piece of the process. Patients without scheduled outpatient appointment following a discharge are twice as likely to be readmitted than those that do.

Family involvement during this process is crucial. Studies indicate that presently $80 \%$ of mentally ill patients either reside with families or have regular contact with them. These relationships are often complicated by the multitude of problems that arise from mental illness and its chronicity. Evidence points to the importance of involvement of family members during discharge process and beyond, while respecting patient's right to privacy. Preparation to support this important relationship is a cornerstone of successful recovery.

\section{Conclusion}

Schizophrenia is a chronic illness that greatly affects not only the diagnosed individual, but also his immediate family and community. The approach to this diagnosis has evolved over time and undergone fundamental changes. Mental hospitals, or asylums initially introduced in 1700 s to deliver a safe, humane care to mentally ill patients were recognized as not being in the best interest of the patient. By the 1950s, institutionalization was demonized due to the inhumane conditions and lengthy, often life-long hospitalizations. Long-term outpatient treatment combined with short acute hospitalizations seemed as a major improvement and quickly become an attractive alternative solution. Initially, the approach appeared successful, with decreasing numbers of occupied hospital beds and relatively steady numbers of readmissions, however closer examination demonstrated that it did not address the problem of the chronicity of the disease.

New policies, transferring financial responsibilities for the mentally ill patient from state hospitals to welfare agencies, led to patient abandonment, as no such shift in responsibility for their care followed. Although in many instances the resources were available for eligible patients, shifting of responsibilities and inadequate communication among them, led to fragmented care. Case managers were introduced to provide a connection among the entities, however critics argued that this was no substitute to the continuity of a uniformed, clinical-team approach.

The shift towards deinstitutionalization presented new challenges. While the trend in general health care in has been to shift responsibility towards the patient and his family, mentally ill patients 
consist of a very special population, often unable to care for themselves. With rising health care costs and decreasing help from the government, many patients are left untreated and lacking basic accommodations. U.S. prisons are filled with growing numbers of mentally ill patients where they live in substandard conditions, receive inadequate care, and are often ridiculed and mistreated. Inaccessibility of quality community health and substitute housing often leads to homelessness, or many patients become "frequent flyers" in jails, psychiatric hospitals, and emergency rooms as the rates of relapse reach $67 \%$.

Responsibility for the chronic, seriously mentally ill patient, over time, has shifted from the institutional care at the state level, to the individual patients and their families, and back to institutionalization in the form of incarceration in jails and prisons.

Discharge planning, which has been identified as a crucial aspect of recovery, must be part of the new paradigm providing answers and possibilities to not only patients, but also families and communities. Patient faced with incarceration are without an option of a release to the community, and do not have the ability to work with patients and their families on long term discharge planning and follow up. Prisons were developed with primary purpose to protect the public safety and are not equipped provide effective psychiatric care past release.

Patients with chronic mental illness represent one of the most vulnerable patient populations. The current trend towards their incarceration leaves them even more disadvantaged. Additional research is required to evaluate this shift, to explore the kind of recovery they can achieve in this setting, and to evaluate the quality of care received while incarcerated. Above all, further research is needed to design and implement interventions to decrease incarcerations in this susceptible group.

\section{References}

1. Macleod S, Elliot L, Brown (2010) What support can community mental health nurses deliver to carers of people diagnosed with schizophrenia? Findings from a review of the literature. International Journal of Nursing Studies 48: 100-120.

2. Hollingshead AB, Redlich FC (2007) Social class and mental illness: a community study (1958). Am J Public Health.

3. Koyanagi C (2007) Learning from history: deinstitutionalization of people with mental illness as precursor to long-term care reform. Henry J. Kaiser Family Foundation, Washington.

4. Goldberg D, Ivbijaro G, Kolkiewicz L, Ohene S (2013) Schizophrenia in primary care. Mental Health in Family Medicine 10: 231-239.

5. Khaleghparast S, Ghanbari B, Kahani S, Malakouti K, SeyedAlinaghi S, et al. (2013) The effectiveness of discharge planning on the knowledge, clinical symptoms and hospitalization frequency of persons with schizophrenia: a longitudinal study in two hospitals in Tehran, Iran. J of Clin Nursing 23: 2215-2222.

6. Bauer M, Fitzgerald L, Haesler E, Manfrin M (2009) Hospital discharge planning for frail older people and their family. Are we delivering best practice? A review of the evidence. J Clin Nurs 18: 2539-2546.

7. Suro G, Weisman De Mamani AG (2013) Burden, interdependence, ethnicity, and mental health in caregivers of patients with schizophrenia. Family Process 52: 299-311.
8. Baker F (1974) From community mental health to human service ideology. AJPH 64: 576-581.

9. Locke BZ (1962) Outcome of first hospitalization of patients with schizophrenia. Public Health Reports 77: 801-805.

10. Rohde P, Sargant W (1961) Treatment of schizophrenia in general hospitals. BMJ 8: 67-70.

11. Wing JK, Denham J, Munro AB (1959) Duration of stay in hospital of patients suffering from Schizophrenia. British Journal of Preventive \& Social Medicine 13: 145-148.

12. Gruenberg EM, Archer J (1979) Abandonment of responsibility for the seriously mentally ill. The Milbank Memorial Fund Quarterly. Health and Society 57: 485-506.

13. Curson DA, Patel M, Liddle PF, Barnes TR (1988) Psychiatric morbidity of a long stay hospital population with chronic schizophrenia and implications for future community care BMJ 297: 819-822.

14. Weinstein RM (1979) Patient attitudes toward mental hospitalization: A review of quantitative research. Journal of Health and Social Behavior 20: 237-258.

15. Melzer D, Hale AS, Malik SJ, Hogman GA, Wood S (1991) Community care for patients with schizophrenia one year after hospital discharge. BMJ 303: 1023-1026.

16. Kanter J, Lamb HR, Loeper C (1987) Expressed emotion in families: A critical review. Psychiatric Serv 38: 374-380.

17. Farina A, Fisher JD, Getter H, Fischer EH (1978) Some consequences of changing people's views regarding the nature of mental illness. J of Abnormal Psy 87: 272-279.

18. Lamb HR, Weinberger LE (2005) The shift of psychiatric inpatient care from hospitals to jails and prisons. J Am Acad Psychiatry Law 33: 529-534.

19. Hawthorne WB, Folsom DP, Sommerfeld DH, Lanouette NM, Lewis M, et al. (2012) Incarceration among adults who are in the public mental health system: Rates, risk factors, and short-term outcomes. Psychiatric Serv 63: 26-32.

20. Gerson LD, Rose LE (2012) Needs of persons with serious mental illness following discharge from inpatient treatment: Patient and family views. Arch Psychiatr Nurs 26: 261-271.

21. Habibi R, Nayer MS, Zadeh MK (2015) Educational needs of families of patients with Schizophrenia: A literature review. International Journal of Medical Reviews 2: 250-255.

22. Nelson EA, Maruish ME, Axler JL (2000) Effects of discharge planning and compliance with outpatient appointments on readmission rates. Psychiatric Services 51: 885-859.

23. Andrews WN, King M H (1972) Amotivational syndrome: The real management problem of schizophrenia. Canadian Med Asso J 106: 1208-1213.

24. (2013) Centers for Disease Control and Prevention. Mental Health Basics.

25. (2015) Centers for Disease Control and Prevention. Stigma and mental illness.

26. Kate N, Grover S, Kulhara P, Nehra R (2014) Relationship of quality of life with coping and burden in primary caregivers of patients with schizophrenia. International Journal of Social Psychiatry 60: 107-116.

27. Knowles J (2003) A separate peace. New York: Scribner, New York, U.S.A.

28. Silverman M (1971) Comprehensive department of psychological medicine: Three-year review of inpatients referred for aftercare visits. BMJ 3: 99-101. 